\title{
Feasibility of radical gastrointestinal tumor resection with simultaneous off-pump coronary artery bypass surgery for patients with severe heart problems: a retrospective cohort study from a single institutional database
}

\author{
Rongrong Jiang ${ }^{1}$, Ziying Xiao ${ }^{1}$, Jiechun Huang ${ }^{1}$, Xiaotian $\mathrm{Sun}^{1}$, Xianglin $\mathrm{Chu}^{1}$, Fangrui \\ Wang ${ }^{1}$, Yiqing Wang ${ }^{1}$, Liewen Pang ${ }^{1}$, and fen luo ${ }^{2}$ \\ ${ }^{1}$ Huashan Hospital Fudan University \\ ${ }^{2}$ Affiliation not available
}

February 18, 2021

\begin{abstract}
Purpose: Clinical treatment of gastrointestinal neoplasms in patients with severe coronary stenosis is difficult, and it remains controversial to perform staged or simultaneous surgeries. The purpose of this study was to retrospectively analyze the feasibility and indications for simultaneous gastrointestinal tumor resection and off-pump coronary artery bypass (OPCAB) graft surgery. Methods: Data collected from a total of five patients, including three patients with gastric cancer and two patients with colorectal cancer, who underwent simultaneous radical cancer resection and OPCAB between September 2010 and October 2019, were retrospectively analyzed. Among these patients, one had an incomplete colonic obstruction. All patients had severe coronary stenosis, and one experienced acute heart failure before surgery. OPCAB was performed first, followed by the radical cancer resection. Results: All five patients were discharged from hospital without perioperative death, major cardiovascular events or anastomotic leakage. The mean postoperative hospital stay was 9.4 days. One patient experienced slight gastrointestinal bleeding after surgery, which improved with conservative treatment. After a mean follow-up of 39 months, two patients with gastric cancer died from tumor metastasis at 28 months and 37 months, while the remaining three patients did not have tumor recurrence or metastasis. None of the patients experienced myocardial ischemia. Conclusion: It is safe and feasible to perform simultaneous $\mathrm{OPCAB}$ and gastrointestinal surgeries on the premise of strictly controlling the indications for patients with gastrointestinal tumors complicated with severe coronary artery stenosis.
\end{abstract}

Type of article: Original article

Feasibility of radical gastrointestinal tumor resection with simultaneous off-pump coronary artery bypass surgery for patients with severe heart problems: a retrospective cohort study from a single institutional database

Authors: Rongrong Jiang, ${ }^{1,}$, Ziying Xiao ${ }^{2},{ }^{*}$, Jiechun Huang ${ }^{1}$, Xiaotian $\mathrm{Sun}^{1}$, Xianglin $\mathrm{Chu}^{1}$, Fangrui Wang $^{1}$, Yiqing Wang ${ }^{1}$, LieWen Pang ${ }^{1, * *},{\text { Fen } \text { Luo }^{3, * *}}^{, *}$

${ }^{*}$ R.J. and Z.X. have contributed equally to this work as first authors.

${ }^{* *}$ L.P. and F.L. have contributed equally to this work as corresponding authors.

\section{Affiliations:}

${ }^{1}$ Department of Cardiothoracic Surgery, Huashan Hospital, Fudan University, Shanghai, P.R. China 
${ }^{2}$ Department of Neurology, Huashan Hospital, Fudan University, Shanghai, P.R. China

${ }^{3}$ Department of General Surgery, Huashan Hospital, Fudan University, Shanghai, P.R. China

\section{**Corresponding authors:}

Liewen Pang, MD

Department of Cardiothoracic Surgery, Huashan Hospital, Fudan University

\#12 Wulumuqi Rd. (M), Shanghai, 200040 P.R. China

Email: plwmd1967@126.com

Fen Luo, MD

Department of General Surgery, Huashan Hospital, Fudan University

\#12 Wulumuqi Rd. (M), Shanghai, 200040 P.R.China

Email: ladouandxiao@me.com

\section{Abstract}

Purpose: Clinical treatment of gastrointestinal neoplasms in patients with severe coronary stenosis is difficult, and it remains controversial to perform staged or simultaneous surgeries. The purpose of this study was to retrospectively analyze the feasibility and indications for simultaneous gastrointestinal tumor resection and off-pump coronary artery bypass (OPCAB) graft surgery.

Methods: Data collected from a total of five patients, including three patients with gastric cancer and two patients with colorectal cancer, who underwent simultaneous radical cancer resection and OPCAB between September 2010 and October 2019, were retrospectively analyzed. Among these patients, one had an incomplete colonic obstruction. All patients had severe coronary stenosis, and one experienced acute heart failure before surgery. OPCAB was performed first, followed by the radical cancer resection.

Results: All five patients were discharged from hospital without perioperative death, major cardiovascular events or anastomotic leakage. The mean postoperative hospital stay was 9.4 days. One patient experienced slight gastrointestinal bleeding after surgery, which improved with conservative treatment. After a mean follow-up of 39 months, two patients with gastric cancer died from tumor metastasis at 28 months and 37 months, while the remaining three patients did not have tumor recurrence or metastasis. None of the patients experienced myocardial ischemia.

Conclusion: It is safe and feasible to perform simultaneous OPCAB and gastrointestinal surgeries on the premise of strictly controlling the indications for patients with gastrointestinal tumors complicated with severe coronary artery stenosis.

Keywords : digestive tract cancer, coronary heart stenosis, simultaneous surgery, OPCAB, gastrointestinal surgery.

\section{Declarations}

\section{Funding}

No funding was declared.

\section{Conflicts of interest/Competing interests}

No competing interests are declared.

\section{Ethics approval}

Not applicable. 


\section{Consent to participate}

Not applicable.

\section{Consent for publication}

Not applicable.

\section{Availability of data and materials}

Not applicable.

\section{Code availability}

Not applicable.

\section{Authors' contributions}

Rongrong Jiang and Ziyin Xiao have contributed equally to this work as first authors. Liewen Pang and Feng Luo have contributed equally to this work as corresponding authors. ALL authors approved the final manuscript.

\section{Introduction}

Gastric cancer and colorectal malignancies, two major cancers that threaten human life, rank sixth and second in terms of global incidence of cancer, respectively, and gastric cancer ranks second in terms of mortality ${ }^{1}$. Cardiovascular disease is the most common risk factor that complicates the radical resection of gastrointestinal tumors in elderly patients ${ }^{2}$. In recent years, with the development of the economy and improvement in health care within China, the average life span has been significantly extended ${ }^{3}$. At the same time, the incidence of cardiovascular diseases has also increased significantly ${ }^{4}$. The number of patients with ischemic heart disease, especially those with multiple coronary arteries severely affected by stenosis, has gradually increased ${ }^{5}$. As such, the number of patients with gastrointestinal tumors complicated by multi-vessel coronary artery disease is also trending upwards.

Studies have confirmed that the incidence of perioperative myocardial ischemia is approximately $40 \%$ for non-cardiac surgery in cardiovascular patients/high-risk patients, which is nine times higher than low-risk patients, and postoperative negative cardiac events are significantly increased ${ }^{6}$. Patients with coronary heart disease, especially those with multiple vessels affected, who only undergo peripheral vascular, chest and abdominal surgery without coronary revascularization, have an increased risk of myocardial infarction and cardiac death ${ }^{7}$. Coronary revascularization can help reduce the risk of heart attack and death in these high-risk patients ${ }^{8}$. Therefore, for patients with gastrointestinal cancer complicated by severe coronary artery stenosis, it has become a difficult surgical problem to achieve complete radical resection of the tumor while reducing the risk, as much as possible, of perioperative myocardial infarction and death. This study retrospectively analyzed the data of five patients who underwent concurrent off-pump coronary artery bypass (OPCAB) and radical resection of a gastrointestinal tumor between September 2010 and October 2019, in order to provide additional insight regarding the treatment of these patients.

\section{Methods}

\section{Patients}

A total of five patients underwent OPCAB and radical resection of a gastrointestinal tumor in Huashan Hospital, affiliated with Fudan University, between September 2010 and October 2019 (Table 1). All five patients were male and the average age was 61.8 years. Three patients with gastric cancer were admitted to hospital due to discomfort in the upper abdomen after eating, among which two patients had accompanying unstable angina pectoris and one patient had severe left heart failure. There were two patients with colon cancer. One of these patients was admitted to hospital due to unstable angina pectoris; preoperative examination revealed low hemoglobin, and colonoscopy revealed a colonic tumor at the hepatic flexure. The second 
patient with colon cancer was admitted due to incomplete intestinal obstruction and unstable angina pectoris. All five patients underwent preoperative evaluations, including clinical history, physical examination, routine blood examination of liver and kidney function, gastroenteroscopy, abdominal and chest computed tomography (CT) scans, and others. All patients were pathologically diagnosed with adenocarcinoma prior to surgery.

The electrocardiogram and/or clinical symptoms of all five patients suggested a history of coronary heart disease. All patients underwent coronary angiography and transthoracic echocardiography before the operation (Table 2), which confirmed severe coronary heart disease including three-vessel, left main, and main-like disease, all requiring coronary artery bypass grafting (CABG). Coronary angiography of Case 5 was shown in Fig.1 Transthoracic echocardiography indicated that the left ventricular ejection fraction (LVEF) was $56.8 \%(45-65 \%)$ on average. According to the preoperative NSQIP-MICA score, the risk of perioperative myocardial infarction and cardiac arrest was extremely high.

Surgical procedures and follow up.

All patients were given lipid-lowering drugs and beta-blocker prior to the operation. Except for case 2, the patients were discontinued from clopidogrel and aspirin seven to eight days before surgery, and low molecular weight heparin (4100 U, q12h) was injected subcutaneously for bridging. During the bridging process, severe angina or chest tightness did not occur in any case, nor did gastrointestinal bleeding occur. Case 2 had severe coronary artery stenosis before surgery and presented with left heart failure, while antiplatelet drugs, cardiotonic diuretics and other drugs did not improve the patient's condition. After implantation of an intra-aortic balloon pump (IABP), the blood flow was stable enough to perform an emergency OPCAB and radical resection of the gastric cancer.

All the patients were operated on by the same group of cardiac and gastrointestinal surgeons. OPCAB was performed first, followed by radical cancer resection of the gastrointestinal tumors. After conventional anesthesia, a median incision was made into the chest to harvest the internal mammary artery, the great saphenous vein, and the left radial artery as graft vessels. Heparin $(1 \mathrm{mg} / \mathrm{kg})$ was administered intravenously before the graft was disengaged. The proximal end of the graft was sutured to the aorta using 5-0 prolene, and the distal end was sutured to the coronary artery using 7-0 prolene. After completion of the grafting, protamine sulfate (1.5x the amount of heparin) was administered for heparin neutralization. After rigorous maintenance of hemostasis and placement of a thoracic drainage tube, the chest was closed. The abdomen was then disinfected again, and a midabdominal incision was made approximately $5 \mathrm{~cm}$ from the lower edge of the chest incision to perform the radical resection of the gastrointestinal tumor. All patients underwent an R0 resection and standard lymph node dissection. Negative pressure drainage was established, and gastric cancer patients were fitted with a nasal nutrition tube (Table 3).

Following the operations, patients were placed in the intensive care unit for monitoring. The IABP was removed shortly after the operation, and the tracheal intubation was removed at the appropriate time. Patients with gastric cancer received enteral nutrient solution, aspirin, clopidogrel, beta-blockers, and lipidlowering drugs through the nasal feeding tube beginning from the first day after surgery. Patients with colorectal cancer received intravenous nutrition and low molecular weight heparin (4100 U, q12h) was injected subcutaneously from the first postoperative day. After eating, the patients were given the above drugs orally. The drainage tube was removed when the pleural mediastinal drainage was less than $200 \mathrm{~mL} /$ day. After confirming that there were no gastrointestinal fistulas, the abdominal drainage tube and enteral feeding tube were removed and the patients were discharged. The patients were prescribed additional medication and were followed up regularly (Table 4).

\section{Results}

Following OPCAB, the hemodynamics of all patients were stable, and the gastric or colon tumor resection was successfully performed without perioperative death. The average length of the operation was $7.47 \mathrm{~h}$ $(6.4-10.0 \mathrm{~h})$, the average number of grafts per patient was $3.2(2.0-5.0)$, the average time spent on ventilation was $13.1 \mathrm{~h}(10.1-16.5 \mathrm{~h})$, and the average postoperative blood transfusion volume was $2.8 \mathrm{U}(2.0-4.0 \mathrm{U})$. The 
average length of stay in the ICU was $15.8 \mathrm{~h}(13.0-19.0 \mathrm{~h})$, and the average length of the entire hospital stay was $9.4 \mathrm{~d}(6.0-13.0 \mathrm{~d})$. None of the patients had major cardiovascular events after the operation, nor did any require an additional operation due to bleeding or gastrointestinal fistulas. Gastrointestinal decompression drainage in case 4 revealed brown fluid on the fourth postoperative day. This was accompanied by melena and decreased hemoglobin, which suggested gastrointestinal bleeding. Antiplatelet drugs were stopped, and conservative treatment was provided. The patient improved after four days. During the discontinuation of antiplatelet drugs, the patient did not experience any cardiovascular symptoms such as chest tightness or shortness of breath. Two patients (case 2 and 3) developed atrial fibrillation after surgery, which improved with medication. Case 5 underwent colostomy surgery two months after the combined operation.

The average follow-up was 39 months (5-115 months). Two patients with gastric cancer died at 28 months and 37 months due to tumor metastasis, and there was no chest tightness or shortness of breath during this period. The remaining patients were alive without cardiovascular events or tumor progression at the end of the follow-up period (Table 5).

\section{Discussion}

For patients with gastrointestinal malignancies and severe coronary stenosis, the choice between staged or simultaneous surgeries is still controversial. Staged radical resection of the tumor following CABG has been the traditional approach in the past ${ }^{9,10}$. However, it has been reported that a second non-cardiac surgery within 30 days has a higher risk of death and cardiovascular complications. In general, it is recommended that the subsequent operation be performed six to 12 weeks after grafting ${ }^{11}$. In addition, the general nutritional status of gastrointestinal tumor patients was lower, and the recovery time after CABG was longer. Takahashi and colleagues reported that the second operation was delayed in three of nine patients who received staged surgery due to slow recovery following $\mathrm{CABG}$, with an average interval of seven weeks ${ }^{12}$. Importantly, the tumor may progress while patients are awaiting radical surgery. Additionally, heparinization during CABG and postoperative antiplatelet therapy may lead to gastrointestinal malignancy bleeding, which could be life-threatening. Therefore, to avoid the above shortcomings of staged surgeries, concurrent surgeries may be a better option. In addition, the concurrent surgeries can also reduce the immunosuppression caused by twice the anesthesia, reduce the long-term recurrence rate of the tumor caused by blood transfusions ${ }^{13}$, reduce the pain experienced by patients, and it has health and economic benefits.

More than 20 patients with gastric cancer and 10 patients with bowel cancer have received simultaneous CABG and radical gastrointestinal tumor resection ${ }^{14-16}$. There were no perioperative deaths, and no occurrences of postoperative myocardial infarction or heart failure. A total of five patients at our center were discharged smoothly without adverse events. There were no perioperative deaths, and no serious cardiovascular events or anastomosis fistulas following the concurrent surgeries. Two of the gastric cancer patients died at 28 and 37 months due to tumor metastasis, which may be related to the late postoperative pathological stage. Our case series suggests that patients with gastrointestinal tumors and severe coronary heart disease who underwent concurrent $\mathrm{OPCAB}$ and radical resection of their gastrointestinal tumors may have better short-term results, and the long-term prognosis may be related to tumor staging.

Although concurrent surgeries have many advantages over staged surgeries, combined surgery often takes a long time and is more traumatic to the patient. Therefore, it is necessary to strictly control the surgical indications for this type of surgery. Shapira et al.reported that CABG in patients with left ventricular ejection fraction $(\mathrm{LVEF})<30 \%$ can be performed with low mortality, but with higher morbidity and longer length of hospital stay compared to patients with LVEF $>30 \%{ }^{17}$. Zhang and colleagues proposed that concurrent surgery is not recommended for patients with LVEF $<45 \%^{18}$, and Davydov and colleagues have stated that LVEF $<20 \%$ is a contraindication for concurrent surgery ${ }^{16}$. However, Takahashi et al. reported that concurrent CABG and radical gastrointestinal tumor resections were safe and feasible in patients with low $\mathrm{LVEF}^{14}$. At present, the ejection fraction $(\mathrm{EF})$ value of patients undergoing concurrent surgery is generally $>30 \%$, and the average LVEF in our study group was $56.8 \%$ (45-65\%). In general, low LVEF does not affect the simultaneous operations, but if it is too low (especially $<20 \%$ ), it may be contraindicated. 
The management of patients with severe coronary stenosis who present with acute heart failure may be a more difficult challenge for cardiac surgeons. Most scholars believe that left heart failure that requires large doses of cardiotonic drugs or mechanical circulatory support is a contraindication to simultaneous surgery, and these patients should be operated on in stages ${ }^{14}$. Among our patients, OPCAB was urgently performed on case 2 because of acute left heart failure. After OPCAB, the patient had stable hemodynamics and no obvious bleeding tendencies, so he immediately underwent radical resection of gastric cancer. This is the first case of heart failure that underwent simultaneous CABG and radical tumor resection, which has provided a potential solution for the treatment of such patients.

In addition to the condition of the heart, the surgery required for the abdominal tumor is also an important factor in considering whether to perform the operations at the same time. Tsuji et al . reported that CABG and total gastrectomy at the same time have a higher risk of mediastinal infection, and proposed that CABG and total gastrectomy should be performed in stages, with the total gastrectomy being performed three to six weeks after $\mathrm{CABG}{ }^{10}$. Takahashi suggested that patients with severe coronary heart disease undergoing resection of high-risk tumors, such as esophageal cancer and pancreatic cancer, should also undergo staged surgeries ${ }^{14}$. In addition, Komokata and colleagues published a report on an 83-year-old patient with chronic obstructive pulmonary disease (COPD) who underwent simultaneous aortic valve replacement and radical gastric cancer surgery, and died of respiratory failure following the operation, suggesting that advanced age and COPD are high risk factors for poor outcomes in simultaneous surgeries ${ }^{15}$.

CABG and percutaneous coronary intervention (PCI) are both strategies of coronary revascularization, but making a choice between the two is still controversial. The SYNTAX trail showed that CABG had a mortality benefit over PCI in patients with multi-vessel disease, particularly in those with diabetes and higher coronary complexity ${ }^{19}$. For patients with coronary heart disease undergoing non-cardiac surgery, it is recommended to implant bare stents instead of drug-eluting stents, because this can shorten the time interval between subsequent operations ${ }^{20}$. The ideal interval to perform non-cardiac surgery after implantation of bare stents is three months, when the principle negative events (death, myocardial infarction, stent thrombosis and revascularization) are lowest ${ }^{21}$. Therefore, CABG may be a more reasonable choice for revascularization compared to PCI for patients with multi-vessel disease undergoing surgery for gastrointestinal cancer. After multidisciplinary discussions between cardiologists and cardiac surgeons, we finally decided to adopt CABG as the strategy of coronary revascularization.

Randomized controlled clinical trials have shown that OPCAB and on-pump CABG have a similar early and late graft patency rate, revascularization rate and long-term prognosis ${ }^{22}$. For surgeons with excellent surgical skills, the incidence of morbidity (stroke, atrial fibrillation and infection) after OPCAB is lower 23. Compared with on-pump CABG, OPCAB can reduce the risk of gastrointestinal bleeding caused by heparinization, reduce the systemic inflammatory response, and will not enhance tumor progression due to cardiopulmonary bypass ${ }^{24}$. Similar to the suggestion offered by Komokata et al. , OPCAB may be more reasonable for cancer patients. The use of arterial grafts is beneficial to the long-term prognosis of CABG, especially the internal mammary artery. The internal mammary artery was anastomosed to the anterior descending branch. The radial artery is the second choice, and its long-term patency is better than vein usage ${ }^{25}$, but inferior to the internal mammary artery ${ }^{26}$. However, it takes longer to obtain arterial grafts than venous grafts. We recommend that it is necessary to combine the prognosis of patient and the state of the surgery to decide which type of graft to use. If the long-term prognosis is poor, a venous graft may be a more appropriate choice. If the tumor stage is early and the life expectancy is long, total arterial grafts should be used as far as possible. The preoperative tumor staging of case 2 indicated that the gastric cancer stage was late and the patient with acute left heart failure underwent emergency CABG, so the great saphenous vein was selected as the grafting vessel. The patient of case 5 was younger, had a relatively early preoperative tumor stage, and has colorectal cancer. Therefore, two arterial grafts from the left internal mammary artery and radial artery were used.

Except in case 2, the remaining four patients in this study were all associated with unstable angina. Before surgery, aspirin and clopidogrel were stopped for seven days according to relevant guidelines, and low 
molecular weight heparin was injected subcutaneously for bridging ${ }^{27}$. Gastric cancer patients were given a nutrient solution and antiplatelet drugs through the nasal feeding tube on the first day after surgery. Patients with colorectal cancer were given intravenous nutrition after surgery, and low molecular weight heparin was given subcutaneously before eating while oral antiplatelet drugs were given after eating. By following this principle of discontinuation and administration, none of the four patients experienced perioperative severe angina pectoris or severe gastrointestinal bleeding. Case 4 showed signs of gastrointestinal bleeding after antiplatelet drugs were given following surgery. When the antiplatelet drugs were stopped and conservative treatment was provided, the patient improved after four days. No cardiovascular symptoms such as chest tightness or shortness of breath were seen during the withdrawal. According to our experience, an indwelling small intestinal nutrition tube placed during the operation has many advantages; not only can nutrition be supplied through the tube as soon as possible to promote the early recovery of digestive tract function, it can also be used to infuse antiplatelet drugs early to reduce the risk of acute thrombosis of the coronary anastomosis.

We found that the concurrent radical resection of the gastrointestinal tumor was performed under stable hemodynamics, and the radical resection of the operation was not affected ${ }^{28}$. The follow-up data also suggest that the overall survival and relapse-free survival after the concurrent surgeries are equivalent to those of radical gastrointestinal surgery alone ${ }^{29}$. A study of concurrent surgery for gastric cancer and CABG suggested that the long-term prognosis depends on the staging status of the gastric cancer at the time of diagnosis ${ }^{10}$.

Anastomotic leakage is a common and serious complication. There has been no significant difference reported in the proportion of anastomotic leakage between staged and simultaneous surgeries ${ }^{15,30}$. However, there are some special considerations for concurrent surgeries, such as the location of the advanced tumor, that influence whether or not to perform the extended radical operation. If there is incomplete colonic obstruction before the operation, the surgeons need to consider the pros and cons to decide whether to anastomose. Tsujiet al . recommended that aggressive concurrent surgical interventions might bring a benefit to the patients whose survival periods are expected to be more than six months ${ }^{10}$. In our group of patients, incomplete colonic obstruction was found preoperatively in case 5, and tumor invasion of a section of the small intestine was discovered during the operation. Considering the high risk of the combined operations in the same period, $\mathrm{OPCAB}+$ colorectal cancer resection + affected small intestinal resection + descending colostomy were performed in the first stage, and then the colon was anastomosed after the patient's condition was improved. In addition, wound infection and treatment are also issues that need to be considered. The incidence of incision infection and mediastinal infection may be reduced by closing the thoracic incision first, re-disinfecting strictly and then performing the gastrointestinal surgery, isolating the thoracoabdominal incision, and prophylactic use of antibiotics prior to the operation. Timely reoperation for debridement, colostomy and omentum packing is conducive to early wound healing and effective control of mediastinal infection ${ }^{10,15}$.

This study still has some limitations. Firstly, because this study is a retrospective analysis and the number of included cases is small, there is a certain bias. Secondly, due to the limitation of the length of follow-up, the long-term effect of the concurrent surgery needs to be further followed up and observed. Additional in-depth studies are necessary to provided more solid evidence.

In summary, for the treatment of patients with gastrointestinal tumors and severe coronary heart disease, concurrent surgery is being accepted by a growing number of surgeons. This study provides a useful exploration of treatment strategies for patients with gastrointestinal tumors and severe coronary heart disease.

\section{References}

1. Fitzmaurice C, Akinyemiju TF, Al Lami FH, Alam T, Alizadeh-Navaei R, Allen C, et al. Global, Regional, and National Cancer Incidence, Mortality, Years of Life Lost, Years Lived With Disability, and DisabilityAdjusted Life-Years for 29 Cancer Groups, 1990 to 2016: A Systematic Analysis for the Global Burden of Disease Study. JAMA Oncol . 2018;4:1553-1568. 
2. Carroll K, Majeed A, Firth C and Gray J. Prevalence and management of coronary heart disease in primary care: population-based cross-sectional study using a disease register. J Public Health Med . 2003;25:29-35.

3. Zhou M, Wang H, Zhu J, Chen W, Wang L, Liu S, et al. Cause-specific mortality for 240 causes in China during 1990-2013: a systematic subnational analysis for the Global Burden of Disease Study 2013.Lancet . $2016 ; 387: 251-72$.

4. Zhao D, Liu J, Wang M, Zhang X and Zhou M. Epidemiology of cardiovascular disease in China: current features and implications. Nat Rev Cardiol . 2019;16:203-212.

5. Yin Z, Zeng C, Zhang X, Yang C, Wang H, Song W, et al. The characteristics of coronary stenosis in 11,267 patients from Southwest China: a retrospective study. J Thromb Thrombolysis . 2018;45:142-150.

6. Mangano DT, Browner WS, Hollenberg M, London MJ, Tubau JF and Tateo IM. Association of perioperative myocardial ischemia with cardiac morbidity and mortality in men undergoing noncardiac surgery. The Study of Perioperative Ischemia Research Group. N Engl J Med . 1990;323:1781-8.

7. Eagle KA, Rihal CS, Mickel MC, Holmes DR, Foster ED and Gersh BJ. Cardiac risk of noncardiac surgery: influence of coronary disease and type of surgery in 3368 operations. CASS Investigators and University of Michigan Heart Care Program. Coronary Artery Surgery Study.Circulation . 1997;96:1882-1887.

8. Eagle KA, Rihal CS, Mickel MC, Holmes DR, Foster ED and Gersh BJ. Cardiac risk of noncardiac surgery: influence of coronary disease and type of surgery in 3368 operations. CASS Investigators and University of Michigan Heart Care Program. Coronary Artery Surgery Study. Circulation . 1997;96:1882-7.

9. Isomura T, Hisatomi K, Koga M, Yamana K, Kinoshita H, Kosuga K et al. [Coronary artery bypass grafting combined with operation for non-cardiac disease]. Nihon Geka Gakkai Zasshi . 1991;92:847-51.

10. Tsuji Y, Morimoto N, Tanaka H, Okada K, Matsuda H, Tsukube T, et al. Surgery for gastric cancer combined with cardiac and aortic surgery.Archives of surgery (Chicago, Ill : 1960) . 2005;140:1109-14.

11. Crawford ES, Morris GC, Jr., Howell JF, Flynn WF and Moorhead DT. Operative risk in patients with previous coronary artery bypass.Ann Thorac Surg . 1978;26:215-21.

12. Takahashi T, Nakano S, Matsuda H, Matsumura R, Sakurai M, Hirose H et al. [Surgical treatments for coronary artery disease associated with cancer: a consideration of simultaneous procedure of coronary artery revascularization and surgery for cancer]. Nihon Geka Gakkai Zasshi . 1989;90:2037-43.

13. Schiergens TS, Rentsch M, Kasparek MS, Frenes K, Jauch KW and Thasler WE. Impact of perioperative allogeneic red blood cell transfusion on recurrence and overall survival after resection of colorectal liver metastases. Diseases of the colon and rectum . 2015;58:74-82.

14. Takahashi T, Nakano S, Shimazaki Y, Kaneko M, Nakahara K, Miyata M, et al. Concomitant coronary bypass grafting and curative surgery for cancer. Surg Today . 1995;25:131-5.

15. Komokata T, Fukueda M, Kaieda M, Ueno T, Iguro Y, Imoto Y et al. Simultaneous operation for cardiac disease and gastrointestinal malignancy. World journal of gastrointestinal surgery . 2014;6:146-50.

16. Davydov MI, Akchurin RS, Gerasimov SS, Polotsky BE, Stilidi IS, Machaladze ZA, et al. Simultaneous operations in thoraco-abdominal clinical oncology. Eur J Cardiothorac Surg . 2001;20:1020-4.

17. Shapira OM, Hunter CT, Anter E, Bao Y, DeAndrade K, Lazar HL et al. Coronary artery bypass grafting in patients with severe left ventricular dysfunction-early and mid-term outcomes. J Card Surg . $2006 ; 21: 225-32$.

18. Zhang W, Liu B, Zhou Y, Wang F, Gu C, Wang Q, et al. Combined surgical treatment of esophageal cancer and coronary heart diseases in elderly patients. World J Surg Oncol . 2018;16:213-213. 
19. Head SJ, Milojevic M, Daemen J, Ahn JM, Boersma E, Christiansen EH, et al. Mortality after coronary artery bypass grafting versus percutaneous coronary intervention with stenting for coronary artery disease: a pooled analysis of individual patient data. Lancet . 2018;391:939-948.

20. Kim HL, Park KW, Kwak JJ, Kim YS, Sir JJ, Lee SJ, et al. Stent-related cardiac events after non-cardiac surgery: drug-eluting stent vs. bare metal stent. International journal of cardiology . 2008;123:353-4.

21. Nuttall GA, Brown MJ, Stombaugh JW, Michon PB, Hathaway MF, Lindeen KC, et al. Time and cardiac risk of surgery after bare-metal stent percutaneous coronary intervention. Anesthesiology . 2008;109:588-95.

22. Puskas JD, Williams WH, O'Donnell R, Patterson RE, Sigman SR, Smith AS, et al. Off-pump and on-pump coronary artery bypass grafting are associated with similar graft patency, myocardial ischemia, and freedom from reintervention: long-term follow-up of a randomized trial.Ann Thorac Surg . 2011;91:1836-42; discussion 1842-3.

23. Sedrakyan A, Wu AW, Parashar A, Bass EB and Treasure T. Off-pump surgery is associated with reduced occurrence of stroke and other morbidity as compared with traditional coronary artery bypass grafting: a meta-analysis of systematically reviewed trials. Stroke . 2006;37:2759-69.

24. Pinto CA, Marcella S, August DA, Holland B, Kostis JB and Demissie K. Cardiopulmonary bypass has a modest association with cancer progression: a retrospective cohort study. BMC Cancer . 2013;13:519-519.

25. Hayward PA, Gordon IR, Hare DL, Matalanis G, Horrigan ML, Rosalion A and Buxton BF. Comparable patencies of the radial artery and right internal thoracic artery or saphenous vein beyond 5 years: results from the Radial Artery Patency and Clinical Outcomes trial. J Thorac Cardiovasc Surg . 2010;139:60-5; discussion 65-7.

26. Ruttmann E, Fischler N, Sakic A, Chevtchik O, Alber H, Schistek R, et al. Second internal thoracic artery versus radial artery in coronary artery bypass grafting: a long-term, propensity score-matched followup study. Circulation. 2011;124:1321-9.

27. Sousa-Uva M, Neumann FJ, Ahlsson A, Alfonso F, Banning AP, Benedetto U, et al. 2018 ESC/EACTS Guidelines on myocardial revascularization.Eur J Cardiothorac Surg . 2019;55:4-90.

28. Shaikh I, Dedhia B, Sangle M, Maru N and Mathur S. Simultaneous radical gastrectomy and coronary artery bypass grafting: a case report.Indian J Surg . 2015;77:159-61.

29. Zhang W, Liu B, Zhou Y, Wang F, Gu C, Wang Q, et al. Combined surgical treatment of esophageal cancer and coronary heart diseases in elderly patients. World J Surg Oncol . 2018;16:213.

30. Zhao J, Han Y, Lei J, Zhou Y, Lu Q, Tian F, et al. Simultaneous esophagectomy and off-pump coronary artery bypass grafting: a practicable approach with good survival. Dis Esophagus . 2017;30:1-5.

\section{Acknowledgments}

None.

Fig.1 Coronary angiography of Case 5. (a) $99 \%$ stenosis of the left anterior descending (LAD) artery and the diagonal artery. (b) $80 \%$ stenosis of the ramus artery. (c) $80 \%$ stenosis of the left circumflex (LCX) artery. (d) $99 \%$ stenosis of the right posterolateral (RPL) artery. (e) $90 \%$ stenosis of right coronary artery (RCA). 

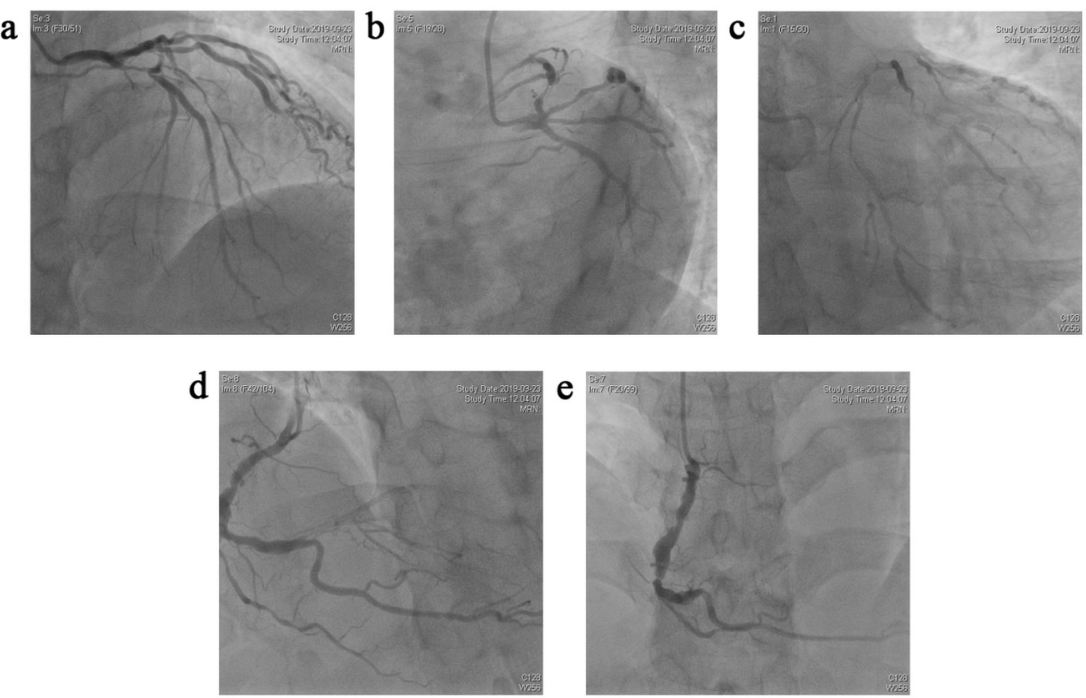

Table 1. Patient baseline cancer-related characteristics.

\begin{tabular}{lllll}
\hline Case ID & Gender & Age $(\mathbf{y r s})$ & Tumor Type & Pre-operative TNM \\
\hline C1 & M & 59 & Right colon cancer & T3N0M0 \\
C2 & M & 76 & Cardiac carcinoma & T3N2M0 \\
C3 & M & 75 & Gastric corpus cancer & T4N0M0 \\
C4 & M & 49 & Gastric corpus cancer & T4N0M0 \\
C5 & M & 50 & Sigmoid cancer & T4N0M0 \\
\hline
\end{tabular}

Abbreviations: M, male; TNM, tumor node metastasis.

Table 2. Patient baseline cardiovascular characteristics.

\begin{tabular}{|c|c|c|c|c|c|c|c|}
\hline \multirow{2}{*}{$\frac{\text { Case ID }}{\mathrm{C} 1}$} & \multirow{2}{*}{$\begin{array}{l}\text { Chief } \\
\text { Com- } \\
\text { plaints }\end{array}$} & \multicolumn{2}{|c|}{$\begin{aligned} \text { Pre-op } \\
\text { ComorbiditiesEKG }\end{aligned}$} & \multicolumn{2}{|c|}{$\begin{array}{l}\text { LVEF } \\
\text { Echocardiograpdiy }\end{array}$} & \multirow{2}{*}{$\begin{array}{l}\text { CAG } \\
\text { Triple } \\
\text { vessels } \\
\text { stenosis }^{1}\end{array}$} & \multirow{2}{*}{$\begin{array}{l}\text { NSQIP- } \\
\text { MICA } \\
(\%) \\
3.73\end{array}$} \\
\hline & & $\mathrm{T} 2 \mathrm{DM}$ & $\begin{array}{l}\text { Depressed } \\
\text { ST Flat or } \\
\text { inversed T } \\
\text { wave }\end{array}$ & $\begin{array}{l}\text { Abnormal } \\
\text { multi- } \\
\text { segment } \\
\text { activity }\end{array}$ & 64 & & \\
\hline $\mathrm{C} 2$ & $\begin{array}{l}\text { Acute } \\
\text { heart } \\
\text { failure }\end{array}$ & $\begin{array}{l}\mathrm{HN}, \\
\text { Historic } \\
\mathrm{MI}\end{array}$ & $\begin{array}{l}\text { Depressed } \\
\text { ST }\end{array}$ & $\begin{array}{l}\text { Abnormal } \\
\text { multi- } \\
\text { segment } \\
\text { activity }\end{array}$ & 65 & $\begin{array}{l}\text { Left main } \\
\text { equivalent } \\
\text { stenosis }^{2}\end{array}$ & 16.97 \\
\hline C3 & $\begin{array}{l}\text { Unstable } \\
\text { angina }\end{array}$ & $\mathrm{HN}$ & $\begin{array}{l}\text { V3-V5 ST } \\
\text { depressed }\end{array}$ & $\begin{array}{l}\text { Decreased } \\
\text { anterior } \\
\text { wall } \\
\text { activity }\end{array}$ & 60 & $\begin{array}{l}\text { Left main } \\
\text { stenosis }\end{array}$ & 5.03 \\
\hline
\end{tabular}




\begin{tabular}{|c|c|c|c|c|c|c|c|}
\hline \multirow{2}{*}{$\frac{\text { Case ID }}{\mathrm{C} 4}$} & \multirow{2}{*}{$\begin{array}{l}\begin{array}{l}\text { Chief } \\
\text { Com- } \\
\text { plaints }\end{array} \\
\begin{array}{l}\text { Unstable } \\
\text { angina }\end{array}\end{array}$} & \multicolumn{2}{|c|}{$\begin{array}{c}\text { Pre-op } \\
\text { Comorbiditie\$EKG }\end{array}$} & \multicolumn{2}{|c|}{$\begin{array}{c}\text { LVEF } \\
\text { Echocardiograpthy }\end{array}$} & \multirow{2}{*}{$\begin{array}{l}\text { CAG } \\
\text { Two } \\
\text { vessels } \\
\text { stenosis }^{3}\end{array}$} & \multirow{2}{*}{$\begin{array}{l}\text { NSQIP- } \\
\text { MICA } \\
(\%) \\
3.07\end{array}$} \\
\hline & & $\mathrm{HN}$ & $\begin{array}{l}\text { Flat or } \\
\text { inversed } \mathrm{T} \\
\text { wave }\end{array}$ & $\begin{array}{l}\text { Abnormal } \\
\text { multi- } \\
\text { segment } \\
\text { activity }\end{array}$ & 50 & & \\
\hline C5 & $\begin{array}{l}\text { Unstable } \\
\text { angina }\end{array}$ & None & $\begin{array}{l}\text { Depressed } \\
\text { ST }\end{array}$ & $\begin{array}{l}\text { Overall } \\
\text { activity } \\
\text { weakened }\end{array}$ & 45 & $\begin{array}{l}\text { Triple } \\
\text { vessels } \\
\text { stenosis }\end{array}$ & 3.13 \\
\hline
\end{tabular}

${ }^{1} 90 \%$ stenosis of LAD, $75 \%$ stenosis of D1, $75 \%$ stenosis of D2, $80 \%$ stenosis of RCA.

${ }^{2} 99 \%$ stenosis of LAD, $99 \%$ stenosis of LCX.

${ }^{3} 90 \%$ stenosis of LAD, $75 \%$ stenosis of PDA.

${ }^{4} 99 \%$ stenosis of LAD and the diagonal artery, $80 \%$ stenosis of the ramus artery and LCX, $99 \%$ stenosis of RPL, $90 \%$ stenosis of RCA.

Abbreviations: Pre-op EKG, preoperative electrocardiogram; LVEF, left ventricular ejection function; CAG, coronary angiography; NSQIP-MICA, American College of Surgeons National Surgical Quality Improvement Program, myocardial infarction or cardiac arrest; T2DM, type 2 diabetes mellitus; HN, hypertension; MI, myocardial infarction; LAD, left anterior descending; D1, first diagonal; D2, second diagonal; RCA, right coronary artery; LCX, left circumflex; PDA, posterior descending artery; RPL, right posterolateral.

Table 3. Surgical information.

\begin{tabular}{llll}
\hline Case ID & Cardiac procedure & Number of Grafts & Surgical Procedure \\
\hline C1 & LIMA-LAD; SVG-D1-D2-RPL-PDA & 5 & Radical resection of right colon cancer \\
C2 & Emergent OPCAB,SVG-LAD;SVG-OM,Y & 2 & Proximal gastrectomy, D2 lymphectom \\
C3 & SVG-D2-LAD & 2 & Total gastrectomy, D2 lymphectomy, R \\
C4 & RA-LAD;SVG-PDA & 2 & Distal gastrectomy, D2 lymphectomy, \\
C5 & LIMA-LAD; RA-PDA; SVG-D1-RAMUS-RPL & 5 & Radical treatment of sigmoid colon can \\
\hline
\end{tabular}

Abbreviations: LIMA, left internal mammary artery; LAD, left anterior descending artery; SVG, great saphenous vein; OPCAB, off-pump coronary artery bypass; D1, $1^{\text {st }}$ branch of the diagonal artery; D2, $2^{\text {nd }}$ branch of the diagonal artery; RPL, right posterior lateral artery; PDA, posterior descending artery; OM, obtuse marginal artery; RA, radial artery

Table 4. Perioperative management of anti-platelet and anticoagulant drugs.

\begin{tabular}{llll}
\hline Case ID & Pre-operation & Pre-operation & Post-operation \\
\hline & Anti-platelet agents & Bridging therapy & Anti-platelet /anticoagulant drugs \\
C1 & withhold for 7d & LMWH** & LMWH POD1-6**, ASA+clopidogrel POD7 to discharge* \\
C2 & ASA+clopidogrel & none & ASA+clopidogrel POD1 to discharge* \\
C3 & withhold for 8d & LMWH** & ASA+clopidogrel POD1 to discharge* \\
C4 & withhold for 8d & LMWH $^{* *}$ & ASA+clopidogrel POD1-3; withhold POD 4-7; resume POD8 to \\
C5 & withhold for 7d & LMWH $^{* *}$ & LMWH POD1-6**, ASA+clopidogrel POD7 to discharge* \\
\hline
\end{tabular}


Abbreviations: ASA, aspirin; POD, day of post-operation; LMWH, low-molecular-weight heparin.

*ASA $100 \mathrm{mg}$ qd + clopigogrel $75 \mathrm{mg}$ qd po

**LMWH 4100 U IH q12h

Table 5. Postoperative patient characteristics.

\begin{tabular}{llllll}
\hline Case ID & Ventilation time(h) & ICU Stay (h) & Postop Complication & Blood Transfusion (U) & LOS (days) \\
\hline C1 & 16 & 18 & None & 2 & 8 \\
C2 & 16.5 & 19 & AF & 4 & 13 \\
C3 & 10 & 13 & AF & 4 & 6 \\
C4 & 10 & 13 & GI bleeding & 2 & 12 \\
C5 & 13 & 16 & None & 2 & 8 \\
\hline
\end{tabular}

Abbreviations: LOS, length of stay; AF, atrial fibrillation; GI, gastrointestinal; ICU, intensive care unit; TNM, tumor node metastasis.

a
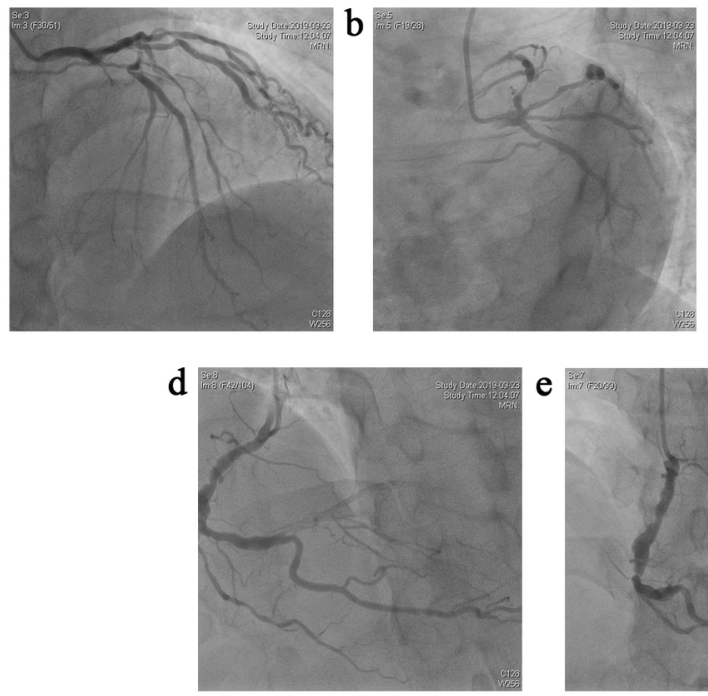
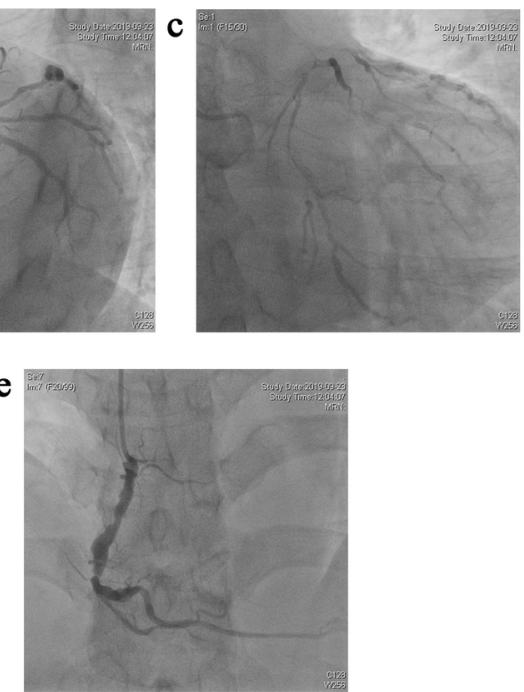

\section{Hosted file}

Table1.pdf available at https://authorea.com/users/384162/articles/509715-feasibility-ofradical-gastrointestinal-tumor-resection-with-simultaneous-off-pump-coronary-arterybypass-surgery-for-patients-with-severe-heart-problems-a-retrospective-cohort-studyfrom-a-single-institutional-database

\section{Hosted file}

Table2.pdf available at https://authorea.com/users/384162/articles/509715-feasibility-ofradical-gastrointestinal-tumor-resection-with-simultaneous-off-pump-coronary-arterybypass-surgery-for-patients-with-severe-heart-problems-a-retrospective-cohort-studyfrom-a-single-institutional-database

\section{Hosted file}


Table3.pdf available at https://authorea.com/users/384162/articles/509715-feasibility-ofradical-gastrointestinal-tumor-resection-with-simultaneous-off-pump-coronary-arterybypass-surgery-for-patients-with-severe-heart-problems-a-retrospective-cohort-studyfrom-a-single-institutional-database

\section{Hosted file}

Table4.pdf available at https://authorea.com/users/384162/articles/509715-feasibility-ofradical-gastrointestinal-tumor-resection-with-simultaneous-off-pump-coronary-arterybypass-surgery-for-patients-with-severe-heart-problems-a-retrospective-cohort-studyfrom-a-single-institutional-database

\section{Hosted file}

Table5.pdf available at https://authorea.com/users/384162/articles/509715-feasibility-ofradical-gastrointestinal-tumor-resection-with-simultaneous-off-pump-coronary-arterybypass-surgery-for-patients-with-severe-heart-problems-a-retrospective-cohort-studyfrom-a-single-institutional-database 